\title{
Production of Ammonia by the Sodium Cyanide Method ${ }^{1,2}$
}

By F. E. Bartell

University of Michigan, ANn ARbor; Michigan

\begin{abstract}
During the war a study was made of the reactions attendant upon the process of steaming Bucher cyanized briquets. It was found that sodium cyanide and sodium cyanate were readily hydrolyzed, giving theoretical yields of ammonia. The iron present in the briquets caused sodium ferrocyanide formation which introduced certain difficulties.

The formation of ferrocyanide starts at the beginning of the steaming process, and reaches a maximum at the temperature of about $475^{\circ} \mathrm{C}$., above which temperature it is decomposed. The rate of decomposition is materially increased with increase in sodium carbonate content. Decomposition of sodium ferrocyanide in the presence of sodium carbonate results in but a slight loss of fixed nitrogen, owing to the formation of cyanide and cyanate, which products are readily hydrolyzed, giving ammonia.

Proper temperature regulation during the process of steaming is highly important. Under a pressure of not over one atmosphere, the limit of pressure in this investigation, the temperature at the beginning of steaming should be about $260^{\circ} \mathrm{C}$. and should nol be allowed to rise above about $650^{\circ} \mathrm{C}$. At higher temperatures ammonia is lost by decomposition.

The rate of steam admission is an important factor. If the steam is added too slowly at first, the temperature will not rise rapidly enough to conform to the conditions that are apparently most favorable. If the steam is added too rapidly, ammonium carbonate is formed with attending difficulties. The quantity of steam added must be sufficient not only to hydrolyze the cyanide and related com-
\end{abstract}

pounds, but also to oxidize the free iron which is present. In order to insure sufficient steam it seems best to use approximately 50 per cent excess over the theoretical amount.

With 4- and 8-in. batch retorts cyanide conversion to ammonia ran from 85 to 100 per cent. With 10 -in. batch retorts (capacity $300 \mathrm{lbs}$. briquets) ammonia recovery of 99 and 100 per cent was obtained. With $16-i n$. retorts (capacity 640 lbs. briquets) yields as high as 93.7 per cent were obtained.

A continuous steamer was developed with an estimated capacity of 100 to $200 \mathrm{lbs}$. of briquets per hour. One run was made with this steamer. The ammonia recovery was 97.8 per cent.

Shortly before the close of this work continuous operations were being carried on. Two cyanizing retorts such as those used at Saltoille were put into operation. Each retort was capable of producing from 30 to $50 \mathrm{lbs}$. of ( 20 to 30 per cent $\mathrm{NaCN}$ ) cyanized briquets per hour. Since the briquets were conveyed from the cyanizer directly to the stcaming retorts, and after steaming back to the cyanizing retorts, the whole process was continuous. With this layout, coke, nitrogen, and steam were used as raw materials, and ammonia was produced in quantities corresponding to the capacity of a single technical unit.

At the time of the Armistice the results of this investigation had shown that the cyanide process offered a feasible and sure method for the production of ammonia. Its advantage lay in the fact that no electrical power was needed. Its main drawback was the relatively high cost of cyanide production.
$\mathbf{S}$ HORTLY after the entry of the United States into the war, three processes for the fixation of atmospheric nitrogen were considered by the War Department as offering practical methods for the production of ammonia and ammonium nitrate. ${ }^{3}$ The processes were the synthetic ammonia (Haber) process, the cyanamide process, and the cyanide process. It is well-known history that the Government constructed plants for the manufacture of ammonia by the first two processes. The result of this work has been well covered in recent chemical literature.

In the United States prior to 1917 none of the above ammonia processes had progressed beyond the experimental stage. It was definitely known that ammonia could be produced by the cyanamide process, and further that such a process was in actual operation in Germany with an estimated production for 1917 of 400,000 tons of cyanamide. It was known also that the synthetic process was in apparently successful operation in Germany, though it had never been successfully operated in this country. The cyanide process was to a still greater extent in the experimental stage. Fur-

1 Received February 2, 1922.

2 This article is printed with the approval of the Chief of the Ordnance, U. S. A., also with the approval of Mr. Edward E. Arnold, President of the Nitrogen Products Co.

The author wishes to express his indebtedness to all the men who so ably and faithfully coöperated in this work and to whom credit is equally due, The men who were most closely associated with the work of this paper are: Mr. Donald V. Lowe (formerly Lieutenant Ord. Dept.), Mr. H. E. Kaiser, Mr. O. E. Madison, and Mr. P. A. Keene; also fullest appreciation should be expressed for the valuable assistance and advice of the officers of the Nitrogen Products Co., particularly to the President, Mr, Edward E. Arnold, whose untiring efforts were largely responsible for the success of this work.

${ }^{3}$ Report of Nitrate Supply Committee, This Journal, 9 (1917), 829. thermore, on paper, the cost of production of ammonia by the cyanide process appeared to be greater than the cost of production by either of the other processes.

Near the close of the year 1917, the War Department, realizing that cyanide was needed for purposes other than the formation of nitrates, decided to attempt the development of the cyanide process. Late in December 1917 plans were made for the construction of a cyanide plant under the direction of the Bureau of Mines; accordingly a plant was built at Saltville, Va., with a capacity of 10 tons sodium cyanide per day. ${ }^{4}$

At the same time an active research on the production of ammonia from cyanide was undertaken by the Nitrate Division of the Ordnance Department, coopperating with the Nitrogen Products Co., of Providence, R. I., at the experimental plant of this company in Greene, R. I.

In January 1918 this work was placed under the direction of the writer (then Captain, Nitrate Div. Ord. Dept.) and Donald V. Lowe (Lieutenant, Nitrate Div. Ord. Dept.), who were later given the assistance of about thirty men, including chemists, chemical engineers, and assistants. With this group much of the work was carried on in shifts, making it possible to conduct continuous experiments over long-time intervals.

Coöperative research was simultaneously carried on at the Geophysical Laboratory in Washington, ${ }^{5}$ and at the U.S. Chemical Plant in Saltville, Va. ${ }^{6}$

The main object of the research at the Greene, R. I., laboratory was the development of a method for the production

4 C. O. Brown, This Journal, 11 (1919), 1010.

J. B. Ferguson and P. D. V. Manning, Ibid., 11 (1919), 946.

${ }^{8}$ G. W. Heise and H. E. Foote, Ibid., $12(1920), 331$ 
of ammonia directly from the cyanide present in the cyanized briquets, such as were to be made by the Bucher process at Saltville. Briefly, it may be stated that the steaming process for conversion of sodium cyanide to ammonia was finally developed in the laboratory at Greene to a point where practically the theoretical yield of ammonia could be obtained by employing batch retorts, and also good yields were obtained with continuous retorts. With 8-in, and 10-in. batch retorts, 100 per cent yields were obtained; with 16-in. batch retorts, with capacity of $600 \mathrm{lbs}$. of briquets, as high as 93.7 per cent yields were obtained.

During this work it became evident that by far the largest part of the cost of ammonia production by this method was due to the high cost of producing cyanized briquets; consequently, the cyanizing end of the process was also investigated in the Greene laboratory, with the result that yields were finally obtained over comparatively long periods which were considerably higher than any yields previously recorded by this method.

\section{SCOPE OF WORK}

The work covered in the research carried on at Greene may be classified under three heads:

1-Iaboratory research work which had to deal for the most part with equilibrium studies.

2-Small scale work in which both cyanizing and steaming reactions were carried out in retorts from 2 in. to $8 \mathrm{in}$. in diameter, these retorts having a briquet capacity of from 2 to $40 \mathrm{lbs}$. of material.

3-Large scale work.

(a) Batch steaming work with retorts 8 in. to 16 in. in diameter with a capacity from 150 to about 600 lbs. of material.

(b) Continuous steaming work, with retorts with a capacity as high as 100 to $200 \mathrm{lbs}$, of briquet material per hour.

(c) Continuous cyanization work with large-sized units, each capable of handling from 50 to 100 lbs. of briquet material per hour.

(d) Final development of a complete and continuous cyanizing and steaming process.

\section{The Cyanide Process}

The cyanide process controlled by the Nitrogen Products Company is the so-called Bucher process ${ }^{7}$ in which nitrogen is passed through a heated mixture of coke, soda ash, and iron. The iron is present merely to serve as a catalytic agent. In practice the coke, soda ash, and iron are brought together in the form of briquets. This material is heated in retorts to a temperature of at least $1000^{\circ} \mathrm{C}$. Pure nitrogen is passed through the mass which gives the following reaction:

$$
\mathrm{Na}_{2} \mathrm{CO}_{3}+4 \mathrm{C}+\mathrm{N}_{2}=2 \mathrm{NaCN}+3 \mathrm{CO}-138,500 \text { cal. }
$$

During this process carbonate is converted into cyanide and the physical properties of the briquets are not seriously altered. In this condition they are well suited to the steaming operations which are later employed to convert the cyanide to ammonia.

\section{Hydrolysis of Cyanide}

The hydrolysis of cyanide may be caused to take place in three stages according to the following reactions:

$$
2 \mathrm{NaCN}+4 \mathrm{H}_{2} \mathrm{O}=2 \mathrm{NH}_{3}+2 \mathrm{HCOONa}+64,000 \text { cal. }
$$

This reaction is exothermic and takes place at low temperatures, $100^{\circ} \mathrm{C}$. to $200^{\circ} \mathrm{C}$. Above $200^{\circ} \mathrm{C}$. sodium formate is converted into oxalate:

$$
2 \mathrm{HCOONa}=\mathrm{Na}_{2} \mathrm{C}_{2} \mathrm{O}_{4}+\mathrm{H}_{2}-3,000 \text { cal. }
$$

This reaction is endothermic. At $360^{\circ} \mathrm{C}$. this reaction will go to completion. At a still higher temperature, somewhat above $400^{\circ} \mathrm{C}$., sodium oxalate is converted into carbonate:

$$
\mathrm{Na}_{2} \mathrm{C}_{2} \mathrm{O}_{4}=\mathrm{Na}_{2} \mathrm{CO}_{3}+\mathrm{CO}-14,800 \mathrm{cal} \text {. }
$$

This reaction is endothermic. The complete reaction may be written:

7 Bucher, This Journal, 9 (1917), 233.
$2 \mathrm{NaCN}+4 \mathrm{H}_{2} \mathrm{O}=2 \mathrm{NH}_{3}+\mathrm{Na}_{2} \mathrm{CO}_{3}+\mathrm{H}_{2}+\mathrm{CO}+46,200$ cal.(5)

The total heat effect of the reaction is exothermic.

If sodium cyanide (or cyanized briquets) is treated with saturated steam, Reaction 2 only takes place and sodium formate is the product of reaction. If dry superheated steam is used, the temperature of the mass rises, as a result of the exothermicity of the reaction. If the cyanide content of the briquets is sufficiently high and the thermal conduction from the retort low, the temperature will be raised sufficiently to result in carbonate formation. The advantage of the latter reaction is that when sodium carbonate is formed in steaming, the briquets again contain the materials necessary for cyanide formation and, owing to their dryness, are again in condition for recyanizing. By employing this method it is possible to pass the briquets through the cyanizing-steaming-cyanizing cycle a number of times (at least three or four) without remaking or refortifying them.

\section{Hydrolysts of Cyanate}

During the cyanization and subsequent cooling of briquets, some sodium cyanide is oxidized to cyanate; also during steaming some cyanate is formed. The presence of cyanate offers very little difficulty.

$2 \mathrm{NaCNO}+3 \mathrm{H}_{2} \mathrm{O}=\mathrm{Na}_{2} \mathrm{CO}_{3}+2 \mathrm{NH}_{3}+\mathrm{CO}_{2}+15,340$ cal. (6)

All of the combined nitrogen in this compound is converted into $\mathrm{NH}_{3}$. The only difficulty comes through the presence of carbon dioxide, which is liberated and which may react with the ammonia gas to form ammonium carbonate. If the carbonate is formed in comparatively large quantities it may cause trouble by plugging the ammonia scrubber system.

\section{Complication of Steaming Due to Presence of Iron}

The presence of iron tends to complicate the reactions which take place during the process of steaming. The principal difficulties encountered are the formation of ferrocyanide and the subsequent reactions of this compound.

Briquets taken directly from the cyanizing retorts and conveyed to the steaming retorts with as little handling as possible adsorbed about 0.2 per cent moisture. If allowed to stand for a number of days they took up a maximum of about 3 per cent.moisture. The rate of adsorption is shown in Table I:

$\begin{array}{ccc} & \text { TABIE I } & \\ \text { No. } & \text { TrEaTMENT of BRIoUETS } & \text { Water Content } \\ 1 & \text { Der cent } \\ 2 & \text { Exposed } 1 \text { hr. } & 0.20 \\ 3 & \text { Exposed } 3 \text { hrs. } & 0.72 \\ 4 & \text { Exposed number of days } & 1.80 \\ 4 & \text { Then dried at } 250^{\circ} \mathrm{C} & 3.04 \\ \end{array}$

The above experiments showed clearly that cyanized briquets should not be handled and exposed to the atmosphere for any appreciable length of time before steaming. It was found that briquets which contained as high as 20 per cent cyanide would, at the very beginning of steaming operations, owing to the iron present, have as high as 40 per cent of total cyanide converted into ferrocyanide. The formation of sodium ferrocyanide and hydrate of sodium ferrocyanide causes not only chemical difficulties, as will be shown later, but also mechanical difficulties. If the hydrate of sodium ferrocyanide is formed rapidly in the early stages of steaming, "setting" of briquets and sticking in the retort occur. With continuous retorts this becomes a serious problem. In this connection the principal facts to be kept in mind are:

1-If briquets containing moisture are used, the hydrate of the ferrocyanide will be formed when the briquets are heated to the temperature suited to its formation.

2-If wet steam is allowed to come in contact with heated briquets the ferrocyanide hydrate will form quickly. 
3-If dry steam is allowed to come in contact with briquets which have not been heated above the temperature limit for ferrocyanide hydrate formation, the temperature of the system will be lowered by heat transfer and the hydrate will form.

In order to avoid these difficulties, the briquets must be heated to a temperature above that suited to hydrate formation and, also, superheated steam must be used.

In much of the steaming work, cyanized briquets which had been made in the Saltville, Va., plant of the Nitrogen Products Company were used. These briquets contained from 12 to 17 per cent iron. In some of the later eyanizing experiments it was found that briquets containing much less iron could be used and still give good yields of cyanide. With such briquets the difficulties due to ferrocyanide formation were greatly decreased.

\section{Principal Secondary Reactions}

The more important secondary reactions in the steaming process are as follows:

1-As the steaming of briquets proceeds, the iron present is oxidized to the oxides $\mathrm{FeO}$ and $\mathrm{Fe}_{3} \mathrm{O}_{4}$. The latter reaction goes practically to completion at a temperature of about $500^{\circ}$ :

$$
3 \mathrm{Fe}+4 \mathrm{H}_{2} \mathrm{O}=\mathrm{Fe}_{3} \mathrm{O}_{4}+4 \mathrm{H}_{2}
$$

2-Iron or the oxides of iron may react with sodium cyanide and steam to form sodium ferrocyanide:

$$
6 \mathrm{NaCN}+\mathrm{Fe}+2 \mathrm{H}_{2} \mathrm{O}=\mathrm{Na}_{4} \mathrm{Fe}(\mathrm{CN})_{6}+2 \mathrm{NaOH}+\mathrm{H}_{2}
$$

$$
\text { or } 6 \mathrm{NaCN}+\mathrm{FeO}+\mathrm{H}_{2} \mathrm{O}=\mathrm{Na}_{4} \mathrm{Fe}(\mathrm{CN})_{6}+2 \mathrm{NaOH}
$$

3-During the process of steaming the ferrocyanide thus formed may be decomposed:

$$
\mathrm{Na}_{4} \mathrm{FeC}_{6} \mathrm{~N}_{6}=4 \mathrm{NaCN}+\mathrm{Fe}+2 \mathrm{C}+\mathrm{N}_{2}
$$

This decomposition is practically complete at a temperature of about $500^{\circ}$. Fixed nitrogen is lost in this reaction.

4-Sodium ferrocyanide may react with other compounds present, such as sodium carbonate or ammonium carbonate. With sodium carbonate the reaction is:

$\mathrm{Na}_{4} \mathrm{FeC}_{6} \mathrm{~N}_{6}+\mathrm{Na}_{2} \mathrm{CO}_{3}=5 \mathrm{NaCN}+\mathrm{NaCNO}+\mathrm{CO}_{2}+\mathrm{Fe}$ (11)

The ritrogen products of this reaction would be hydrolyzed by steam so no loss of nitrogen would result.

5-In the presence of free iron ammonia is dissociated:

$$
2 \mathrm{NH}_{3}=\mathrm{N}_{2}+3 \mathrm{H}_{2}
$$

The active decomposition of ammonia begins at about the upper limit of temperature needed for the completion of the steaming reaction. In practice no serious loss of ammonia results from this reaction.

6-A loss of carbon through oxidation by steam results at low temperatures through the reaction:

$$
\mathrm{C}+2 \mathrm{H}_{2} \mathrm{O}=\mathrm{CO}_{2}+2 \mathrm{H}_{2}-41,560 \text { cal. }
$$

and at higher temperatures through the well-known gas reaction:

$$
\mathrm{C}+\mathrm{H}_{2} \mathrm{O}=\mathrm{CO}+\mathrm{H}_{2}-42,330 \text { cal. }
$$

A large excess of steam should be avoided, since not only is carbon wasted but in addition the system is cooled owing to the endothermicity of the reaction.

These reactions are the principal ones which take place during the process of steaming. Other reactions are possible and other reactions do actually occur, giving compounds not included in the above equations; none of the other reactions, however, have introduced serious difficulties into the process. Ideal reactions for the entire process are as follows:

$$
\begin{gathered}
\mathrm{Na}_{2} \mathrm{CO}_{3}+4 \mathrm{C}+\mathrm{N}_{4}=2 \mathrm{NaCN}+3 \mathrm{CO} \\
2 \mathrm{NaCN}+4 \mathrm{H}_{2} \mathrm{O}=2 \mathrm{NH}_{3}+\mathrm{Na}_{2} \mathrm{CO}_{3}+\mathrm{H}_{2}+\mathrm{CO} \\
\text { or } 4 \mathrm{C}+\mathrm{N}_{2}+4 \mathrm{H}_{2} \mathrm{O}=2 \mathrm{NH}_{3}+\mathrm{H}_{2}+4 \mathrm{CO}
\end{gathered}
$$

Theoretically the only raw materials necessary for the entire process are coke, nitrogen, and steam. The products from reaction being $\mathrm{NH}_{3}, \mathrm{H}_{2}$, and $\mathrm{CO}$, the two latter gases are by-products that in practice should be available in the form of combustible gases which would aid in keeping up either the temperature of the steaming or the temperature of the cyanizing reactions.

\section{Results}

Although the writer's own research work as well as that being carried on at the Geophysical Laboratory had shown that high pressures aid in the steaming process, it was decided to attempt the development of a process which would operate at atmospheric pressure in order to avoid the various mechanical difficulties attendant upon working at high pressures; also, at this time, the writer was limited in large scale work to a steam pressure of but $15 \mathrm{lbs}$. per sq. in.

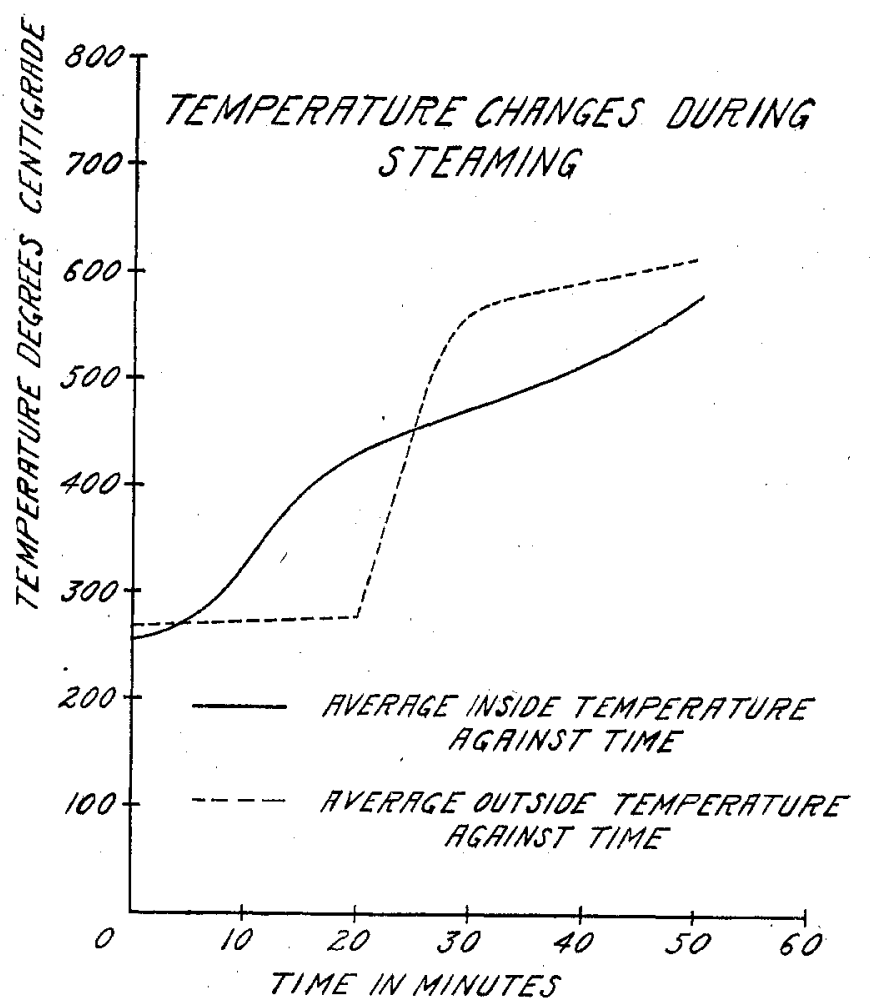

Fig. 1

Practically all work herein described was carried out either at atmospheric pressure or at the pressure of approximately one atmosphere. With batch retorts very nearly theoretical yields of ammonia from sodium cyanide were obtained. With the continuous retorts certain difficulties were at first encountered, both mechanical and chemical, due principally to ferrocyanide formation. These difficulties had been largely overcome at the time of the conclusion of the investigation (November 1918).

In the following discussion some of the results obtained with small retorts ( 4 in. and $8 \mathrm{in}$.) will be given, inasmuch as these results are typical and tend to throw light on the progress of the reactions during the process of steaming.

\section{Extent to Which Temperatures of the Steaming Reac- tion Are Self-Sustaining}

Series of experiments were undertaken in order to determine to what extent ammonia recovery could be carried on without the extension of heat. Briquets of 18 to 20 per cent cyanide content were used.

In these experiments $35 \mathrm{lbs}$. of briquets were placed in an 8-in. retort, the whole system was heated to a given temperature, the external temperature was then held constant, steam was turned on, and the temperature of the reactive mass noted. 
In Table II the results from one series of runs are given. These show the maximum internal temperature attained in each case, as also the per cent recovery of ammonia.

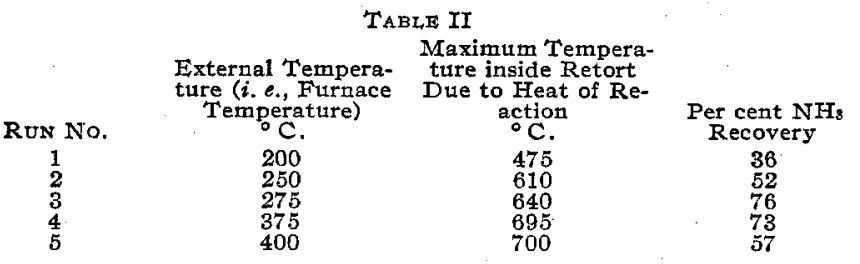

As steam was admitted to the retort the temperature rose. The rate of temperature increase depended upon the rate of steam admission and upon the rate of thermal conduction from the retort. As the steam was passed into the retort the maximum temperature was reached, after which the temperature again fell fairly rapidly and became so low that the ręaction became sluggish, and ammonia evolution practically ceased. The maximum yield of ammonia was obtained with a temperature of about $650^{\circ} \mathrm{C}$; ; at temperatures higher than this considerable ammonia was lost through decomposition.

The rate of steam admission at the various stages of the reaction was important. Our results indicated that while a fairly large amount of steam was desirable in the early stage of the reaction, a large excess should be avoided. Best recoveries were obtained when but a slight excess of steam (not over 50 per cent) in every stage of the reaction was used.

The most satisfactory procedure was to bring the briquet mass to a temperature of from $260^{\circ}$ to $275^{\circ}$, admit steam not too rapidiy, then, after the temperature of the system had risen to about $450^{\circ} \mathrm{C}$., to apply external heat, causing the rate of temperature increase to remain practically constant until the end of the reaction had been reached.

\section{Progress of Reactions}

Experiments carried out with 4-in. batch retorts had shown that practically complete ammonia recovery could be obtained in from 50 to 60 min. A series of runs was made with a retort of this type to follow the progress of the various reactions which occur in the steaming of cyanized briquets. Ten pounds of briquets were placed in each retort for each run. The temperature was raised to $260^{\circ}$ and steam was then admitted. Each run was started under the same conditions and kept as nearly as possible under the same conditions throughout its extent. The periods of steaming were carried on progressively. The first run was carried on for 10 min., after which it was stopped and an analysis of the materials present made. The next run lasted for $20 \mathrm{~min}$., the next run $30 \mathrm{~min}$., the next $40 \mathrm{~min}$., and the last $50 \mathrm{~min}$. The data obtained in these runs are shown in Figs. 1 to 4, inclusive.

\section{Temperature $v s$. Time}

The average temperature values for the various time intervals of the above-described set of experiments are plotted in the curves in Fig. 1. The briquet material within the retort was first brought to a temperature equilibrium which was practically the same as the external temperature $(i . e$. , the temperature of the furnace chamber). The external temperature was held constant at $260^{\circ}$ for a period of $20 \mathrm{~min}$. During that time the temperature of the briquet material was raised by the heat of reaction. At the end of $20 \mathrm{~min}$. the internal temperature had risen to nearly $440^{\circ}$; near the end of this period, however, the rate of temperature rise had become much less rapid. The external temperature was now stepped up. At the end of $30 \mathrm{~min}$. the external temperature was about $565^{\circ}$, while the internal temperature had risen to but $475^{\circ}$. By gradually raising the external tem- perature throughout the remainder of the run, the internal temperature was likewise caused to rise gradually.

The rate of temperature increase shown in these curves represents what has been proved by repeated experience to be a desirable rate to observe when steaming briquets in a 4 -in. retort. Had stepping up the external temperature been delayed, the internal temperature would have reached a maximum (due to the heat of reaction), and a lag in the curve, or even a drop in it would have resulted. The slope of the time-

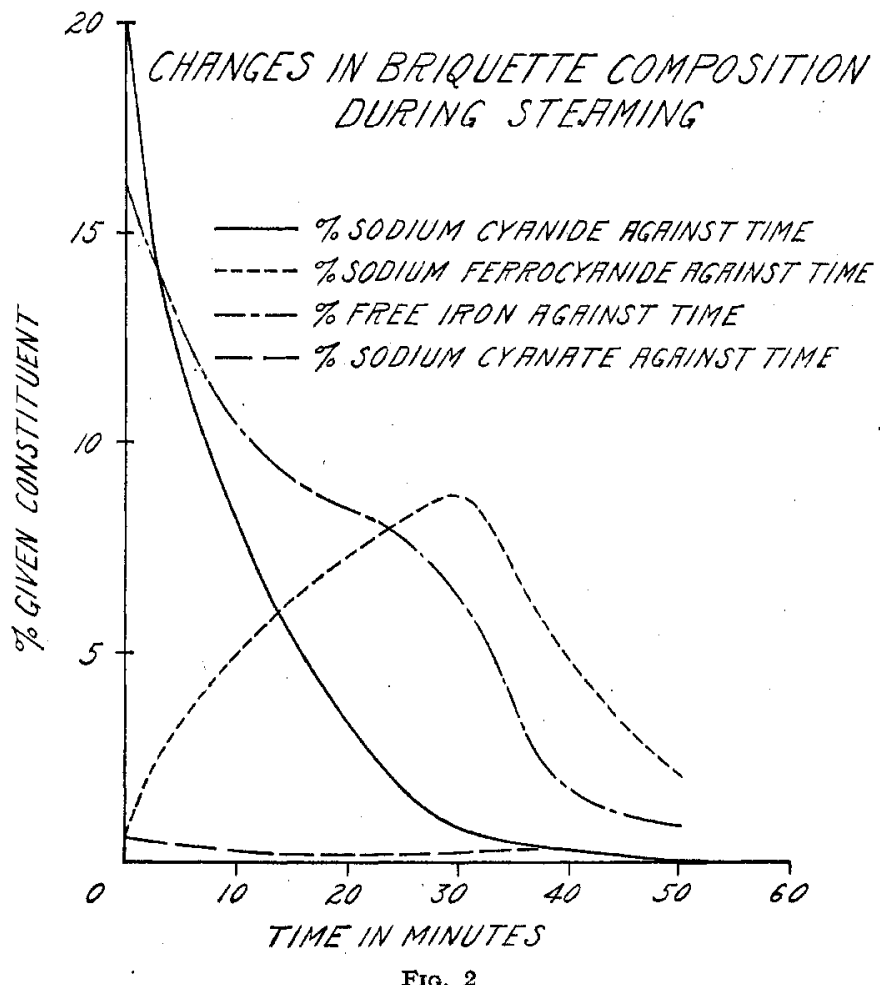

temperature curve depends for most part upon two factors: first, rate of steam admission; second, cyanide content of briquets. Briquets with high cyanide content gave a rapid temperature rise in the early stages of the reaction.

\section{Per cent of Constituent vs. Time}

In Fig. 2, the per cent of constituent is plotted as ordinate while the time in minutes is plotted as abscissa.

The original analysis of the briquets was as follows:

\begin{tabular}{|c|c|c|c|}
\hline \multicolumn{2}{|c|}{ Per cent } & \multicolumn{2}{|c|}{ Per cent } \\
\hline $\mathrm{FaC}$ & 20.07 & $\mathrm{Na}_{2} \mathrm{CO}_{3}$ & 36.4 \\
\hline & 0.48 & Free iron & 16.4 \\
\hline $\mathrm{C}_{6} \mathrm{~N}_{6}$ & 0.00 & Carbon & 21.7 \\
\hline
\end{tabular}

SODIUM CYANIDE-At the beginning of steaming the briquets contained 20.07 per cent $\mathrm{NaCN}$, at the end of the first $10 \mathrm{~min}$. but 7.98 per cent, and at the end of $30 \mathrm{~min}$. but 0.63 per cent. The ammonia recovery at the end of this period was but 41.4 per cent of theoretical. That the fixed nitrogen must be in some form other than $\mathrm{NaCN}$ or $\mathrm{NH}_{3}$ is shown by the fact that, although but 3 per cent of the original sodium cyanide remained in briquets, 58.6 per cent of the theoretical ammonia had not been accounted for. This shows also that one is not justified in calculating ammonia liberated in hydrolysis of sodium cyanide in briquets by taking as a basis of calculation the amount of sodium cyanide remaining undecomposed in the briquets.

SODIUM CYANATE-The sodium cyanate content of the original briquets was 0.48 per cent. With beginning of steaming 
this value dropped to approximately 0.2 per cent where it remained until late in the period of steaming. The fact that the amount of cyanate remained so constant makes it appear that we may have an equilibrium condition and that a considerable amount of fixed nitrogen may pass through this stage. During the later periods of steaming the tempo-

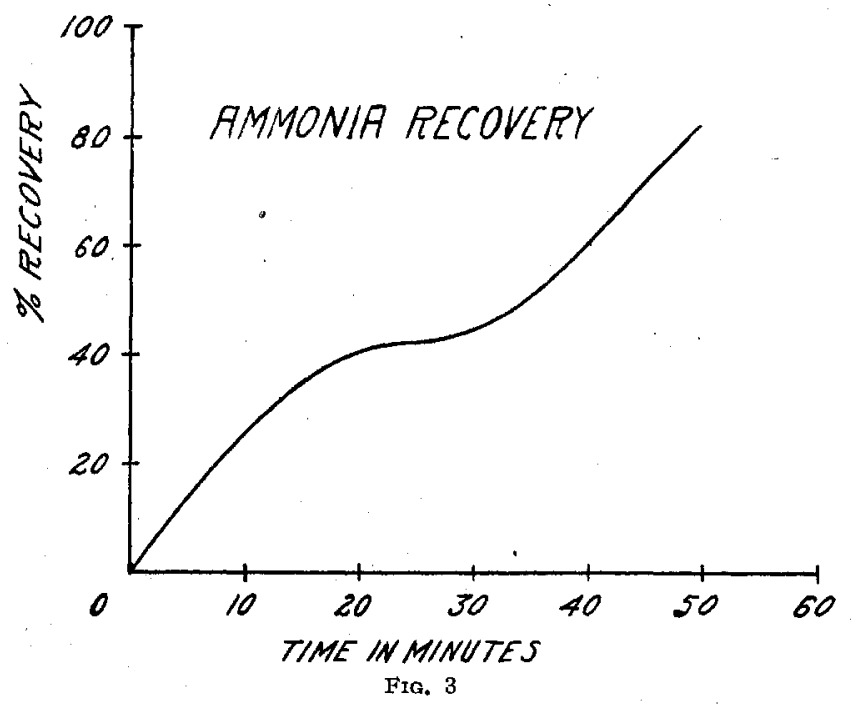

rary formation of $\mathrm{NaCNO}$ must be fairly active, as a result of a reaction between the $\mathrm{Na}_{4} \mathrm{FeC}_{6} \mathrm{~N}_{6}$ and $\mathrm{Na}_{2} \mathrm{CO}_{3}$. This is shown by the active liberation of $\mathrm{CO}_{2}$ gas. (Equation 22.)

SODIUM FERROCYANTDE-It was appreciated early in the research that, during an intermediate stage in the steaming reaction, not all the fixed nitrogen could be accounted for. In the early stages, as also in the later stages, practically all the fixed nitrogen could be accounted for. This fact justified the belief that nitrogen-bearing compounds must be formed during the steaming process. An investigation brought out the fact that sodium ferrocyanide is formed and that the greater percentage of the nitrogen, though not all, 8 can thus be accounted for.

Formation of ferrocyanide begins at the beginning of steaming. It increases rapidly in amount and reaches a maximum at a temperature of about $475^{\circ}$; above this temperature it is decomposed. Complete decomposition does not result during the $60-\mathrm{min}$. steaming period unless a temperature of about $600^{\circ} \mathrm{C}$. is reached and maintained throughout the last $30 \mathrm{~min}$. The rate of decomposition is dependent also upon the amount of sodium carbonate present. For a given temperature the rate of decomposition is materially increased with increase in sodium carbonate content. Considerable time is always required to drive off the last traces of ammonia. In the curve in Fig. 2, at the end of 50 min. about 2 per cent ferrocyanide remained in the briquets, while the recovery of ammonia (Fig. 3) at this point had reached 84.8 per cent. IRON-At the beginning of steaming the briquets contained 16.4 per cent free iron. Oxidation began at once and continued throughout the run. At the end of $20 \mathrm{~min}$. (temperature about $433^{\circ} \mathrm{C}$.) over half the iron had been oxidized. As the temperature was raised the rate of oxidation increased; $\mathrm{Fe}_{3} \mathrm{O}_{4}$ was now formed. At the end of $50 \mathrm{~min}$., but 0.77 per cent free iron remained.

At the conclusion of a steaming run practically all the iron present in the briquets was in the form of oxide. This fact does not hinder the recyanization of the steamed briquets, for it has been found that, even though pure, finely

8 The writer has not as yet been able to determine in what forms all nitrogen exists during this period. divided iron is used in the making of briquets, this iron becomes almost completely oxidized during the process of kneading and drying. During the process of cyanization this oxide is reduced (in some instances only partly) and serves its function as a catalyst in the reaction. The oxidation of iron during steaming offers no disadvantages except that carbon must later be used up in order to reduce the oxide when the briquets are subjected to the process of recyanizing. As far as the total effect on steaming is concerned, the oxidation of iron is advantageous in that the reaction is highly exothermic:

$$
3 \mathrm{Fe}+4 \mathrm{H}_{2} \mathrm{O}=\mathrm{Fe}_{3} \mathrm{O}_{4}+4 \mathrm{H}_{2}+200,800 \mathrm{cal} \text {. }
$$

and is the source of much of the internal heat which is generated during steaming.

\section{Ammonia Recovery vs. Time}

The rate of ammonia evolution (Fig. 3) was high during the first $20 \mathrm{~min}$. of the reaction; at the end of this period the temperature had reached $433^{\circ}, 83$ per cent of the cyanide had disappeared, and had formed 6.67 per cent ferrocyanide, while the ammonia recovery was but 39.5 per cent of the theoretical. During the next 10-min. interval, in which the temperature had increased to $473^{\circ}$, the ammonia evolution was low; but 1.9 per cent of the total ammonia was given off. During this interval the cyanide content had dropped to very nearly a minimum, while the ferrocyanide content had risen to a maximum.

Above this temperature the rate of evolution again increased very nearly to its original value. It is noted that this increase in evolution of gas begins with the decomposition of ferrocyanide and, further, that the high evolution of gas is a direct result of the decomposition of the sodium ferrocyanide.

\section{Composition of Gases Evolved during Steaming}

Curves showing the rate of gas evolution during steaming operations are given in Fig. 4.

At the end of the 10-min. period the gas composition was 95 per cent $\mathrm{H}_{2}, 0.7$ per cent $\mathrm{N}_{2}, 4.3$ per cent $\mathrm{CO}$. This gas composition indicated that for most part the following reactions were in progress:

$$
\begin{gathered}
2 \mathrm{NaCN}+.4 \mathrm{H}_{2} \mathrm{O}=2 \mathrm{NH}_{3}+\mathrm{Na}_{2} \mathrm{CO}_{3}+\mathrm{H}_{2}+\mathrm{CO} \\
\text { and } \mathrm{C}+\mathrm{H}_{2} \mathrm{O}=\mathrm{CO}+\mathrm{H}_{2}
\end{gathered}
$$

At the end of the 30-min. period the gas composition was 1.3 per cent $\mathrm{N}_{2}, 5.4$ per cent $\mathrm{CO}, 93.3$ per cent $\mathrm{H}_{2}$; Reaction 19 was decreasing in extent and Reaction 21

$$
\mathrm{Na}_{4} \mathrm{FeC}_{6} \mathrm{~N}_{6}=4 \mathrm{NaCN}+\mathrm{Fe}+2 \mathrm{C}+\mathrm{N}_{2}
$$

was beginning. At the end of the 50-min. period the gas composition was: $\mathrm{N}_{2} 1$ per cent, $\mathrm{CO} 2.7$ per cent, $\mathrm{CO}_{2} 8.1$ per cent, $\mathrm{H}_{2} 88.2$ per cent.

This analysis shows that very little $\mathrm{Na}_{4} \mathrm{FeC}_{6} \mathrm{~N}_{6}$ was decomposing according to Equation 21, but instead was reacting according to Equation 22:

$\mathrm{Na}_{4} \mathrm{FeC}_{6} \mathrm{~N}_{6}+\mathrm{Na}_{2} \mathrm{CO}_{3}=5 \mathrm{NaCN}+\mathrm{NaCNO}+\mathrm{Fe}+\mathrm{CO}_{2}$

These results indicate why it is possible to obtain high yields of ammonia even though the sodium cyanide of briquets may be converted to sodium ferrocyanide.

\section{Comparison of Valie on Curves}

The time factors of all the curves have been plotted as abscissas, and all on the same scale. It is possible therefore to compare directly all corresponding points on these different curves.

\section{LaRge Scate Work}

Repeated experimental runs made with an 8-in. batch retort had shown that from 85 to 100 per cent ammonia recovery could be attained. It further appeared that from $\mathbf{9 5}$ 